\title{
RESTING AND ACTION POTENTIAL OF SINGLE MUSCLE FIBRES
}

\author{
TARO FURUKAWA* \\ Department of Physiology, Osaka City Medical School
}

Ling and Gerard $(1,2)$ succeeded in measuring the resting potential of single muscle fibres by inserting a microelectrode into them and worked out the effects of external $\mathrm{K}^{+}$concentrations on that potential. This technique was improved by Nastuk and Hodgkin (3), so that the measurements of action potential as well as resting potential became possible.

In the present report some theoretical considerations were attempted concerning the effects of $\mathrm{K}^{+}$concentrations on the resting potential, based upon the author's experimental results.

\section{METHODS}

Frogs ( $R$. nigromaculata) or toads (Bufo vulgaris) were used in all experiments. The sartorius muscle was excised and was stretched with its deeper surface upward on a cork plate which was fixed to the bottom of a Petri-dish filled with Ringer solution. The indifferent electrode was made of $\mathrm{Ag}-\mathrm{AgCl}$ and dipped into the Ringer solution.

The microelectrodes had external diameters less than $1 \mu$ at the tip, and were made from hard glass capillary tubes, after the description of Nastuk and Hodgkin (3). They were filled with a $3 \mathrm{M} \mathrm{KCl}$ solution by boiling in it. The integrity of the tip of the microelectrode was proven under the microscope before and after each experiment. The electrical resistance of microelectorodes used were between 10 and $30 \mathrm{M} \Omega$. It was frequently measured during the experiment, and those with higher resistances were discarded.

The potential changes were observed and photographed on the c.r.o. after direct-coupled 3 stage balanced amplification. The pre-amplifier of cathode follower connection (3) was used to reduce the input capacity. The grid current of 954 tube used in this stage was under $1 \times 10^{-10} \mathrm{~A}$. The input capacity of the pre-amplifier calculated from the response to square voltage, was $3 \mathrm{pF}$. If the capacity at the electrode tip (3) was added, the total input capacity amounted to $5 \mathrm{pF}$ : thus, when a microelectrode has a resistance of $15 \mathrm{M} \Omega$, the time constant of input circuit becomes $75 \mu \mathrm{sec}$.

The experimental arrangement is shown in fig. 1. One of the 954 tubes of the pre-amplifier was mounted on the vertical movement of a microscope and could be moved up and down with the attached microelectorode. The stimula-

Received for publication August 11, 1953.

*古河太郎 


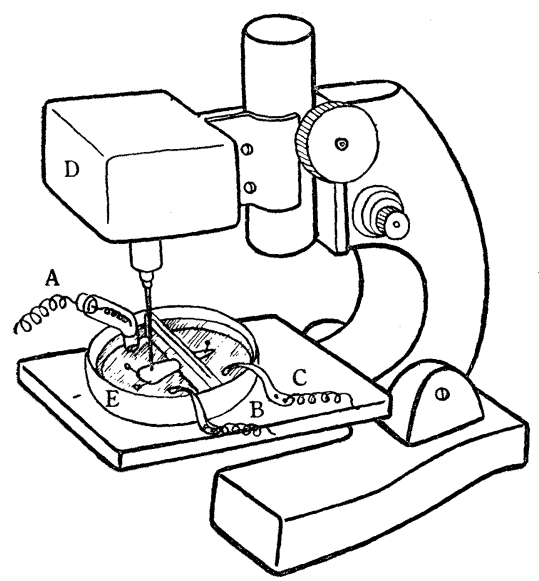

FIG. 1. Experimental arrangements.

$A$ : Indifferent electrode.

$B, C$ : Stimulating electrodes.

$D$ : Box containing a 954 tube.

$E$ : Petri-dish in which Ringer solution is filled (upper surface of the sartorius muscle is just beneath the fluid level). tion of muscle was made by sending a single break induction shock through two silver wires, each dipped into one of two separate Ringer pools divided by a bakelite plate. The muscle was stretched tightly through a hole which was left open between the cork plate and a shallow groove on the lower edge of the bakelite plate.

The experiments were performed between April to November 1952.

Normal Ringer solution used in this experiment was prepared as follows:

$\begin{array}{lc}\mathrm{NaCl} & 114.0 \mathrm{~mm} \\ \mathrm{KCl} & 2.5 \\ \mathrm{CaCl}_{2} & 1.8 \\ \mathrm{NaHCO}_{3} & 2.4\end{array}$

The equal mol of $\mathrm{KCl}$ was substituted for $\mathrm{NaCl}$ where $\mathrm{K}^{+}$concentration was elevated than normal.

\section{RESULTS}

\section{Measurement of resting potential (RP) and action potential (AP)}

Fig. 2 shows a typical example of RP and AP measurements. $A$ is the level of potential when the electrode tip is placed in Ringer fluid outside the fibre at the beginning of experiment. Then the microelectrode is lowered and when the tip touches the muscle the spot of c.r.o. moves slightly. By further lowering of a few $\mu$, the electrode tip is pushed into the fibre and at the same time the spot of c.r.o. moves downward abruptly to level $B$. This is because the interior of the fibre membrane is negative in reference to its outside. Then an induction shock is delivered to the muscle, and AP apears. The peak of AP overshoots the $A$ level. In almost all cases the electrode is dislodged by the contraction following the spike, and the second elevation of potential is observed. But this does not disturb the main features of the action potential. A full course of action potential was observed in rare cases in which the electrode was not dislodged from the fibre (fig. $2, b$ ). When the electrode tip escapes the fibre partially, the potential level does not return to the original $A$ level, so the electrode was somewhat elevated after each stimulation in order to make sure if the new potential level $D$ (see fig. $2, a$ ) is equal to the original $A$ level. If $D$ differed from $A$ by more than $1 \mathrm{mV}$, the result of that measurement was discarded.

\section{Normal values of $R P$ and $A P$}

There were some random variations in the measured potential values, more 


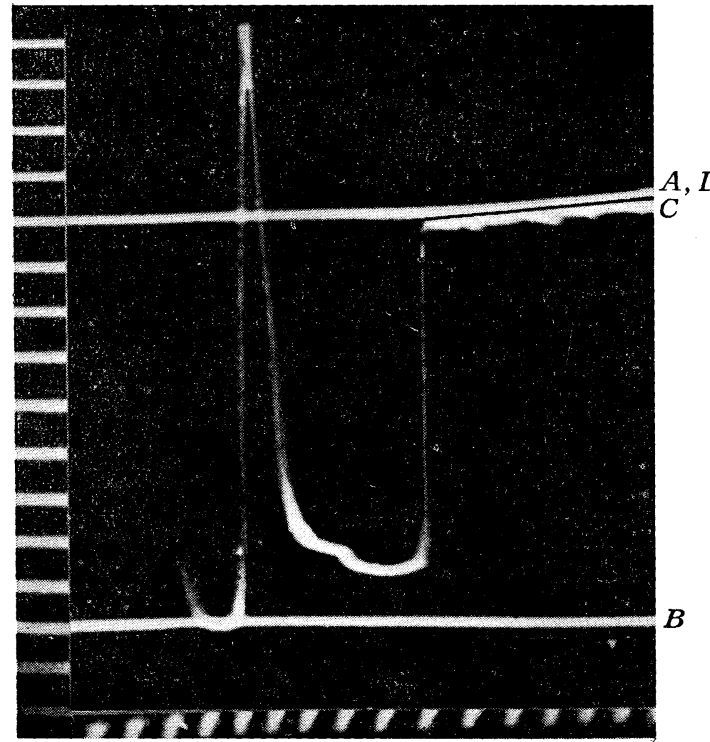

(a)

FIG. 2

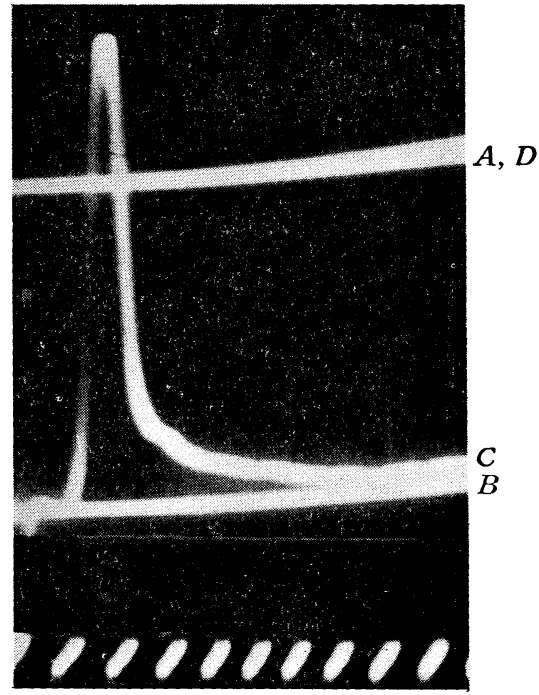

(b)

(a) $\mathrm{RP}$ and $\mathrm{AP}$ at $18^{\circ} \mathrm{C}$. Micrcelectrode resistance, $6 \mathrm{M} \Omega$. Ordinate scale, $10 \mathrm{mV}$ steps from voltage calitrater. Abscissa, 2 msec. $A, D$ microelectrode outside fibre at beginning and end of experiment; $B$, microelectrode inside resting fikre. $C$, the microelectrode was dislodged by the contraction imperfectly following the spike.

(b) $\mathrm{RP}$ and $\mathrm{AP}$ at $21^{\circ} \mathrm{C}$. Microelectrode resistance $15 \mathrm{M} \Omega$. $\mathrm{RP}, 78 \mathrm{mV}, \mathrm{AP}, 113 \mathrm{mV}$. $A, D, B$ as in $(a)$, in $C$ microelectrode inside fibre also after the spike.

or less conspicuous in one and the same muscle. The causes of these variations can be roughly divided into two. Firstly, the potential value may differ in individual fibres. In an inadequate muscle preparation this factor may become considerable. On closer observation, such a muscle often showed fibrillation following a single twitch evoked by an electrical or mechanical stimulus, the fact which was always used by the author as a reliable criterion for knowing whether the preparation was usable or not. It was impossible to make measurements in the hot season (from June to September), because all the excised nuscles showed fibllilation of this kind. Secondly, there is randomness that comes from the measuring procedure. In repeating the measurements on the same muscle, a uniform value of potential cannot be obtained if the electrode is pushed into the same part of the muscle fibre. It is because the fibre membrane is injured by repeated punctures and the electrode tip is not sealed into the membrane, so that leakage current flows and the potential changes irregularly. To avoid this, the muscle was as a rule moved a little before each puncture and the potentials were measured each time at different points of the muscle. In the following study the author adopted all the measured values acquired by repeated puncture to avoid the voluntary selection, but those cases which showed resting potentials below $60 \mathrm{mV}$ were omitted because such a low value 


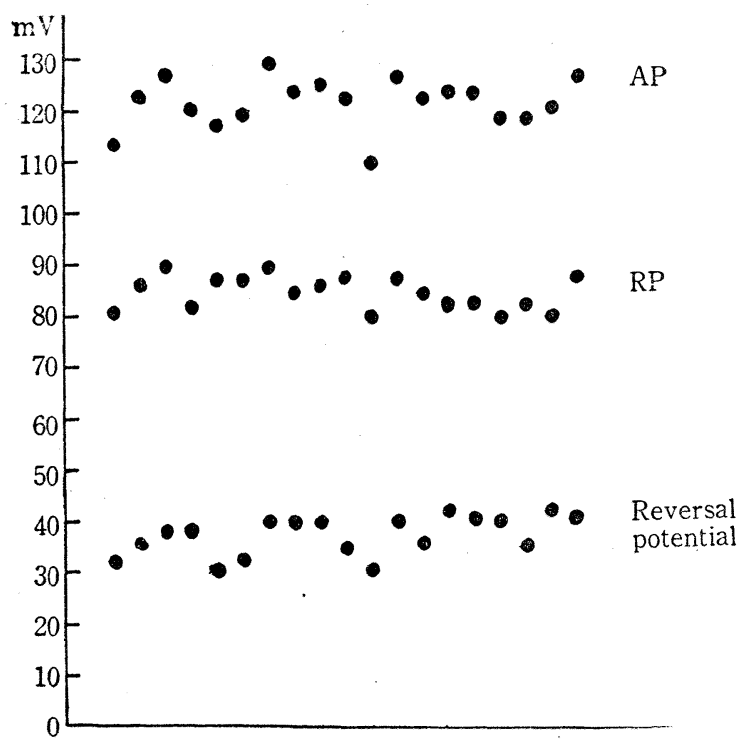

was attributable to an inadequate sealing. In fig. 3 are shown the measured potential values obtained in an experiment. A random variation of this degree was usually encountered in this study. Table 1 shows the results of measurements on twelve muscles.

FIG. 3

When RP and AP are meas. ured repeatedly on the same muscle, measured values exhibit some random variations as are typically shown in this figure.

The mean value of the RP is $84.1 \mathrm{mV}$, maximum and minimum of the measured values being 92 and $75 \mathrm{mV}$. On the other hand, the mean value of the $\mathrm{AP}$ is $117.4 \mathrm{mV}$ and that of the reversal potential is $33.0 \mathrm{mV}$. The maximal measured value of the AP is $134 \mathrm{mV}$ and that of the reversal potential is 50 $\mathrm{mV}$, and minimal ones are 101 and $15 \mathrm{mV}$ respectively.

3. Relation between RP and AP

Fig. $4(a)$ demonstrates the relations between $\mathrm{RP}$ and $\mathrm{AP}$, and $(b)$ those between RP and the reversal potential. In both RP are taken as abscissae.

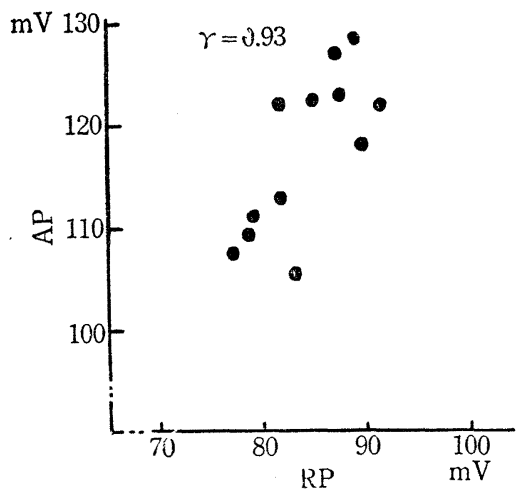

(a)

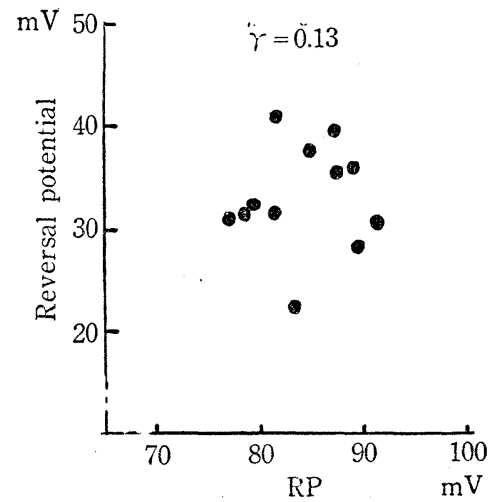

(b)

FIG. 4

(a) Correlogram between RP and AP. (b) Correlogram between RP and reversal potential. $\gamma:$ correlation coefficient. 
It is clearly seen from these figures that positive correlation exists between RP and AP (correlation coefficient is 0.93 ), while little correlation exists between $\mathrm{RP}$ and the reversal potential (correlation coefficient is 0.13 ).

\section{Relation between $R P$ and the external $K^{+}$concentration}

When the $\mathrm{K}^{+}$concentration of Ringer solution bathing the muscle is raised, $\mathrm{RP}$ begins immediately to decrease and arrives at a new fixed potential level after three or five minutes, which in ordinary cases, is maintained almost constant with only a slight drop during a few hours.

The dots in fig. 5 demonstrate changes of RP of a frog's sartorius muscle when the external solution which is bathing the muscle was changed successively to the one having a higher $\mathrm{K}^{+}$concentration. Five or more measurements of the potential were made between 5 and 15 minutes after each change of the external solution and their mean values were shown in the figure. Logarithms of the concentrations of the external $\mathrm{K}^{+}$are taken as abscissae and the potential values as ordinates. Linear relationship exists between $\mathrm{RP}$ and external $\mathrm{K}^{+}$concentration in ranges where the $\mathrm{K}^{+}$concentration is higher than $10 \mathrm{~mm}$. The inclination of the line corresponds to about $45 \mathrm{mV}$ change of potential to ten-fold change of $\mathrm{K}^{+}$concentration. The same results were also obtained by similar experiments on toad's sartorius muscles.

Now in the reverse process, i.e., when a muscle is returned to normal Ringer after it has been

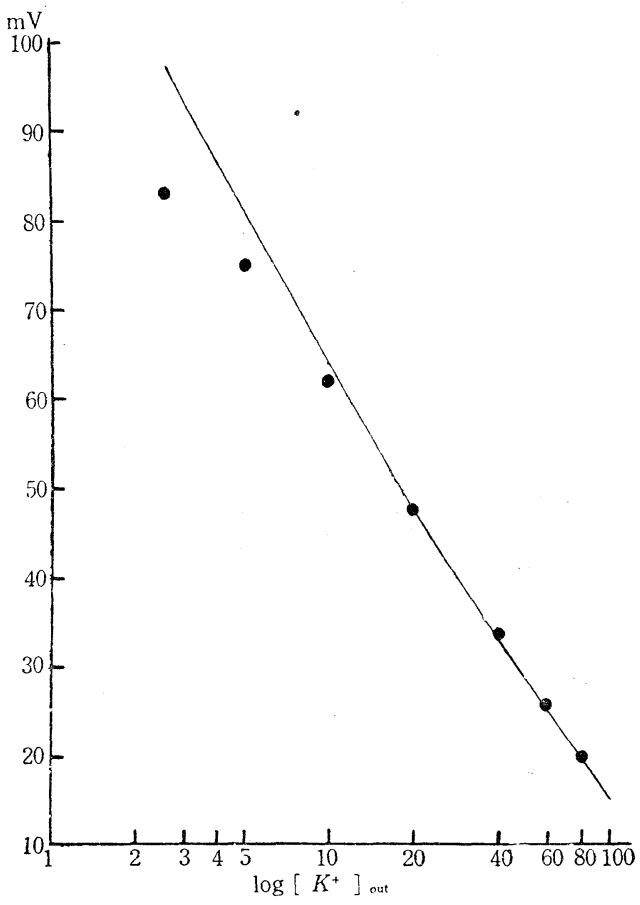

FIG. 5. Relation between RP and the external concentrations of $\mathrm{K}^{+}$.

Dot : measured values.

Line: calculated values (from table 2). immersed for a certain period in a solution of high $\mathrm{K}^{+}$concentration, a very long period is generally needed for the recovery of RP. For example, although a relatively rapid recovery of RP within several minutes is seen when the muscle is immediately returned to normal Ringer after immersion in a solution of $5 \mathrm{~mm} \mathrm{~K} \mathrm{~K}^{+}$for five minutes, about half of an hour or more is needed for the recovery after it is immersed in a solution of $10 \mathrm{~mm} \mathrm{~K} \mathrm{~K}^{+}$for ten minutes. After immersion in solutions of higher $\mathrm{K}^{+}$concentrations, cases were often encountered in which full recovery of RP was not achieved. 


\section{DISCUSSION}

\section{Normal values of $R P$ and $A P$}

Average values of $\mathrm{RP}$ and $\mathrm{AP}$ at the temperature range of $18 \sim 24^{\circ} \mathrm{C}$. are 84.1 and $117.4 \mathrm{mV}$ in the present investigation. The values obtained by Nastuk and Hodgkin (3) are 88 and $119 \mathrm{mV}$ at $18^{\circ} \mathrm{C}$. Although the author's values are 4 and $2 \mathrm{mV}$ lower respectively, the differences are so small that a special meaning can hardly be given to it. Random variations of the measured values, however, are somewhat larger in the present investigation, for in the author's method, the microelectrode was pushed into the muscle at random without visual control, some increase in the randomness of the measured values seemed unavoidable.

\section{Relation between $R P$ and $A P$}

The reversal potential is defined here as the difference between AP and RP. That is:

$$
\mathrm{RP}+\text { reversal potential }=\mathrm{AP} .
$$

Now, in the preceeding section it has been shown that there is no correlation between RP and the reversal potential. Consequently, AP per se seems to be no independent variable, but a sum of two independent variables ( $R P$ and the reversal potential). And from this view point it is well understandable that random variations in the measured values are greater in AP than in two

TABLE 1. RP and AP of Muscle Fibres in Ringer Fluid

\begin{tabular}{|c|c|c|c|c|c|c|c|c|c|}
\hline \multirow{2}{*}{ No. } & \multirow{2}{*}{$\begin{array}{l}\text { Temp. } \\
\left({ }^{\circ} \mathrm{C} .\right)\end{array}$} & \multirow{2}{*}{$\begin{array}{l}\text { Resist- } \\
\text { ance } \\
\text { of } \\
\text { elec- } \\
\text { trode } \\
(\mathrm{M} \Omega) \\
\end{array}$} & \multirow{2}{*}{$\begin{array}{c}\text { Number } \\
\text { of } \\
\text { meas- } \\
\text { ure- } \\
\text { ments }\end{array}$} & \multicolumn{2}{|l|}{$\mathrm{RP}$} & \multicolumn{2}{|l|}{$\mathrm{AP}$} & \multicolumn{2}{|c|}{$\begin{array}{l}\text { Reversal } \\
\text { potential }\end{array}$} \\
\hline & & & & $\mathrm{mV}$ & $u^{1)}$ & $\mathrm{mV}$ & $\mathrm{u}$ & $\mathrm{mV}$ & $\mathrm{u}$ \\
\hline $\begin{array}{l}1 \\
2 \\
3 \\
4\end{array}$ & $\begin{array}{l}24 \\
23 \\
20 \\
21\end{array}$ & $\begin{array}{l}7 \\
5 \\
7 \\
5\end{array}$ & $\begin{array}{r}19 \\
10 \\
6 \\
10\end{array}$ & $\begin{array}{l}85.0 \pm 1.6^{2)} \\
81.6 \pm 1.8 \\
83.0 \pm 5.0 \\
88.7 \pm 2.1\end{array}$ & $\begin{array}{r}11.0 \\
6.3 \\
23.6 \\
9.1\end{array}$ & $\begin{array}{l}122.5 \pm 2.4 \\
112.9 \pm 3.1 \\
105.5 \pm 2.5 \\
128.6 \pm 6.0\end{array}$ & $\begin{array}{r}26.2 \\
19.2 \\
5.9 \\
70.2\end{array}$ & $\begin{array}{l}37.5 \pm 1.9 \\
31.3 \pm 1.7 \\
22.5 \pm 3.3 \\
35.9 \pm 3.7\end{array}$ & $\begin{array}{r}15.0 \\
5.6 \\
26.3 \\
26.3\end{array}$ \\
\hline $\begin{array}{l}5 \\
6 \\
7 \\
8\end{array}$ & $\begin{array}{l}21 \\
21 \\
20 \\
18\end{array}$ & $\begin{array}{r}15 \\
18 \\
6 \\
15\end{array}$ & $\begin{array}{l}6 \\
5 \\
3 \\
5\end{array}$ & $\begin{array}{l}77.0 \pm 4.0 \\
87.2 \pm 3.8 \\
78.3 \pm 6.3 \\
79.0 \pm 5.0\end{array}$ & $\begin{array}{r}15.4 \\
9.2 \\
6.3 \\
15.5\end{array}$ & $\begin{array}{l}107.7 \pm 7.4 \\
127.0 \pm 2.3 \\
109.6 \pm 6.3 \\
111.0 \pm 9.0\end{array}$ & $\begin{array}{r}51.8 \\
3.3 \\
6.3 \\
50.0\end{array}$ & $\begin{array}{l}31.0 \pm 4.7 \\
39.6 \pm 2.2 \\
31.3 \pm 1.5 \\
32.0 \pm 7.2\end{array}$ & $\begin{array}{r}19.8 \\
3.0 \\
0.3 \\
32.5\end{array}$ \\
\hline $\begin{array}{r}9 \\
10 \\
11 \\
12\end{array}$ & $\begin{array}{l}18 \\
18 \\
18 \\
18\end{array}$ & $\begin{array}{r}10 \\
6 \\
6 \\
6\end{array}$ & $\begin{array}{l}7 \\
4 \\
5 \\
5\end{array}$ & $\begin{array}{l}81.3 \pm 6.0 \\
87.5 \pm 5.0 \\
91.4 \pm 4.4 \\
89.6 \pm 2.8\end{array}$ & $\begin{array}{r}38.9 \\
9.7 \\
11.8 \\
5.4\end{array}$ & $\begin{array}{lr}122.0 \pm 9.7 \\
122.8 & 12.5 \\
122.0 & 6.1 \\
118.0 & 8.9\end{array}$ & $\begin{array}{r}103.0 \\
60.9 \\
23.5 \\
48.5\end{array}$ & $\begin{array}{l}40.7 \pm 6.3 \\
35.2 \pm 9.8 \\
30.6 \pm 2.8 \\
28.4 \pm 6.1\end{array}$ & $\begin{array}{r}42.9 \\
36.9 \\
4.9 \\
23.3\end{array}$ \\
\hline \multicolumn{4}{|c|}{ Average (12 muscles) } & 84.1 & 14.7 & 117.4 & 42.6 & 33.0 & 21.5 \\
\hline
\end{tabular}

1) u: unbiased estimate of variance

2) Numerals in this column (and those in two others representing potential values) indicate the means of observed values in each experiments and the ranges within which the true values are expected to fall with the probability of $95 \%$.

For example, $85.0 \pm 1.6$ indicates that, the mean of 19 measurements is $85.0 \mathrm{mV}$, and the true value of RP is expected to exist between 86.6 and $83.4 \mathrm{mV}$ with the probability of $95 \%$. 
others (see table1). The membrane theory assumes that RP is determined by the ratio of inside and outside concentrations of $\mathrm{K}^{+}$. Recently Huxley, Hodgkin, Katz, etc. $(3,4,5)$ have presented the so called Sodium-theory of excitation, in which the reversal potential is said to be determined by the ratio of outside and inside concentrations of $\mathrm{Na}^{+}$. The results described above are well interpreted by these theories.

\section{Relations between RP and external $K^{+}$concentration}

The chemical compositions of the muscle fibre and its external medium have been well worked out by Boyle and Conway $(6,7)$. Schematically they are illustrated by the simple diagram in fig. 6 , where $\mathrm{A}^{-}$represents a group of organic anions.

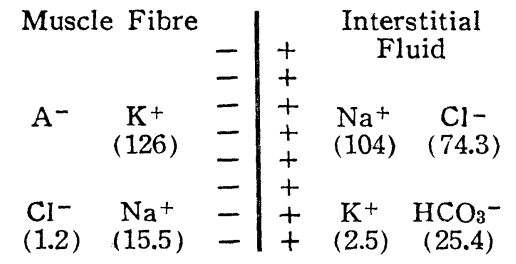

FIG. 6. Schematic diagram representing the distribution of principal ions between muscle fibre and interstitial fluid of frog (from Boyle and Conway (6)).

$\mathrm{A}^{-}$: organic anions.

Number in parenthesis shows concentration of each ion.

The membrane is known to be permeable to $\mathrm{K}^{+}$, so that to explain the large difference in concentration of this ion in both sides, it was supposed for a long time to be impermeable to both $\mathrm{Na}^{+}$ahd $\mathrm{Cl}^{-}$. Conway (7) has shown, however, that the fibre-membrane is readily permeable to $\mathrm{Cl}^{-}$, and has explained the unequal distribution of $\mathrm{K}^{+}$and $\mathrm{Cl}^{-}$as a result of Donnan equilibrium imposed by the organic anions within the fibre, to which the membrane is impermeable. Thus with a membrane permeable to $\mathrm{K}^{+}, \mathrm{Cl}^{-}, \mathrm{HCO}_{3}^{-}$, and $\mathrm{OH}^{-}$, the distribution of these ions should follow the equation:

$$
\frac{\left[\mathrm{K}^{+}\right]_{\text {in }}}{\left[\mathrm{K}^{+}\right]_{\text {out }}}=\frac{\left[\mathrm{Cl}^{-}\right]_{\text {out }}}{\left[\mathrm{Cl}^{-}\right]_{\text {in }}}=\frac{\left[\mathrm{HCO}_{3}^{-}\right]_{\text {out }}}{\left[\mathrm{HCO}_{3}^{-}\right]_{\mathrm{in}^{\mathrm{a}}}}=r \text {. }
$$

In an excised muscle which is immersed in normal Ringer, a large part of $\mathrm{HCO}_{3}{ }^{-}$within fibre exchanges with $\mathrm{Cl}^{-}$, but concerning $\mathrm{K}^{+}$there is no movement across the membrane. Now the ratio of $\mathrm{K}^{+}$concentration is equal to $126 / 2.5=50$ which when substituted in the following equation:

$$
\begin{aligned}
E & =\frac{R T}{F} \ln \frac{\left[\mathrm{K}^{+}\right]_{\text {in }}}{\left[\mathrm{K}^{+}\right]_{\text {out }}} \\
& =58 \log \frac{\left[\mathrm{K}^{+}\right]_{\text {in }}}{\left[\mathrm{K}^{+}\right]_{\text {out }}} \mathrm{mV}, \quad\left(18^{\circ} \mathrm{C} .\right) .
\end{aligned}
$$

The equilibrium potential of $\mathrm{K}^{+}$becomes $99 \mathrm{mV}$. This calculated value is considerably higher than the actual $R P$ which is $84 \mathrm{mV}$ in this paper or $88 \mathrm{mV}$ in Nastuk and Hodgkin. The system, however, is in thermodynamic equilibrium so long as the fibre-membrane is impermeable to $\mathrm{Na}^{+}$as well as to organic anions, and if $\mathrm{Na}^{+}$should invade the fibre, the equilibrium will be broken and $\mathrm{K}^{+}$will leak out through the membrane. Actually, when an excised muscle is placed in a low $\mathrm{K}^{+}$medium (2.5 $\mathrm{mm}$ etc.), there is a steady loss of this ion 
from the fibre, and the maintenance concentration of external $\mathrm{K}^{+}$concerning excised muscles is said to be $29 \mathrm{~mm}$ (7). Because such permeability of the membrane to $\mathrm{Na}^{+}$works to decrease the RP, observed values of RP become lower than the calculated ones. In the region, however, in which external $\mathrm{K}^{+}$ concentration is higher, coincidence of calculated values and observed ones is expected, since the system is in equilibrium. Now when a muscle is immersed in the Ringer solutioos which contain higher $\mathrm{K}^{+}$than normal, $\mathrm{K}^{+}$does not enter the fibre, if it is assumed that the fibre-membrane is not premeable to both $\mathrm{Na}^{+}$ and $\mathrm{Cl}^{-}$, so that $\mathrm{K}^{+}$concentration within the fibre remains unchanged.

In such a case it is calculated from equation (2) that the potential changes $58 \mathrm{mV}$ per ten-fold change of external $\mathrm{K}^{+}$concentration. Such a value does not fit the experimental one $(c a .45 \mathrm{mV})$. On the other hand, according to Conway's theory, an equal amount of $\mathrm{K}^{+}$and $\mathrm{Cl}^{-}$should enter the fibre until the following equilibrium condition is reached.

$$
\left[\mathrm{K}^{+}\right]_{\mathrm{in}}\left[\mathrm{Cl}^{-}\right]_{\text {in }}=\left[\mathrm{K}^{+}\right]_{\text {out }}\left[\mathrm{Cl}^{-}\right]_{\text {out }} \text {. }
$$

TABLE 2. Relation between $\mathrm{RP}$ and the External $\mathrm{K}^{+}$Concentrations

\begin{tabular}{c|c|c|c|c}
\hline & \multicolumn{3}{|c|}{ Calculated value } & Measured value \\
\cline { 1 - 5 }$\left[\begin{array}{c}{\left[\mathrm{K}^{+}\right]_{\text {out }}} \\
(\mathrm{mM})\end{array}\right.$ & $\begin{array}{c}{\left[\mathrm{K}^{+}\right] \text {in }} \\
(\mathrm{mM})\end{array}$ & $r$ & $\begin{array}{c}\mathrm{E} \\
(\mathrm{mV})\end{array}$ & $\begin{array}{c}\mathrm{RP} \\
\mathrm{mV})\end{array}$ \\
\hline 2.5 & 120 & 48.0 & 97.4 & 83 \\
5 & 122.5 & 24.5 & 80.6 & 75 \\
10 & 127 & 12.7 & 63.8 & 62 \\
20 & 136 & 6.8 & 48.1 & 48 \\
40 & 149 & 3.7 & 33.1 & 34 \\
60 & 162 & 2.7 & 24.9 & 26 \\
80 & 173 & 2.2 & 19.7 & 20 \\
100 & 183 & 1.8 & 15.1 & - \\
\hline
\end{tabular}

The concentration of $\mathrm{K}^{+}$within the fibre when the muscle is equilibrated with the Ringer solution containing various amounts of $\mathrm{K}^{+}$are calculated from this principle, and corresponding potential values are calculated from equation (2). These results are shown in table 2. In these calculations the internal concentrations of $\mathrm{K}^{+}$and $\mathrm{Cl}^{-}$equilibrated with the normal Ringer are assumed for the sake of simplicity, to be 120 and $2.5 \mathrm{~mm}$ respectively. In table 2 , it is demonstrated that the calculations fit well with experimental values in the range where the external $\mathrm{K}^{+}$concentration is higher than $10 \mathrm{~mm}$. In fig. 5 the calculated values are shown by a line. Incidentally, when $\mathrm{KCl}$ enters the fibre in this way, the osmotic pressure of the inner fluid rises and as a result water is drawn in and the volume of the muscle increases (7). It is not now clear whether this phenomenon has any effect on the potential value, but presumably its effect is not so large since it does not change the internal concentration of $\mathrm{K}^{+}$considerably. At all events, it is of much interest that a new equilibrium of ionic concentration is established within a few minutes after the external $\mathrm{K}^{+}$ concentration is increased.

On the other hand, as is described in the results, recovery of $\mathrm{RP}$ after returning to a low external $\mathrm{K}^{+}$concentratlon is a markedly slower process. This 
is presumably because, the above mentioned process, i.e., increase of the internal concentration of $\mathrm{K}^{+}$and the swelling of the muscle fibres, invade the deeper layers and when the muscle is returned to $\mathrm{K}^{+}$poor solutions, that $\mathrm{K}^{+}$again leaks out from the interior of the muscle and consequently an unexpected high concentration of $\mathrm{K}^{+}$may be produced in the neighbourhood of the muscle fibres in the surface layer.

\section{SUMMARY}

1. Resting potential (RP) and action potential (AP) of single muscle fibres were measured by means of a microelectrode inserted into them. The frog's sartorius muscles were employed. The average RP was $84.1 \mathrm{mV}$, and the average $\mathrm{AP}$ was $117.4 \mathrm{mV}$ at the temperature range of $18 \sim 24^{\circ} \mathrm{C}$.

2. RP decreased linearly with the logarithmic increase of the external $\mathrm{K}^{+}$ concentrations in the range higher than $10 \mathrm{~mm}$, and the inclination of that line corresponds to the change of $45 \mathrm{mV}$ per ten-fold change of $\mathrm{K}^{+}$concentrations. The results were explained under the assumption that the distribution of $\mathrm{K}^{+}$, $\mathrm{Cl}^{-}$etc. between the muscle fibre and its surroundings followed the Donnanequilibrium.

The author wishes to thank Prof. Y. Hosoya and Prof. T. Otani (Kyoto University) for their invaluable help in this investigation.

\section{REFERENCES}

1. LING, G. AND GERARD, R. W. The normal membran potential of frog sartorius fibres. J. cell. and comp. physiol. 34: 333, 1949.

2. LING, G. AND GERARD, R. W. External potassium and the membrane potential of single muscle fibres. Nature 165: 113, 1950.

3. NASTUK, W. L. AND Hodgkin, A. L. The electrical activity of single muscle fibres. J. cell. and comp. physiol. 35: 39, 1950.

4. HodGKIN, A. L. AND KATZ, B. The effect of sodium ions on the electrical activity of the giant axon of the squid. J. of physiol. 108: 37, 1949.

5. HUXLEY, A. F. AND STAEMPFl. R. R. Effects of $\mathrm{K}^{+}$and $\mathrm{Na}^{+}$on resting and action potentials of single myelinated nerve fibres. ibid. 112: 496, 1951.

6. BOYLE, P. J. AND CONWAY, E. J. Potassium accumulation in muscle and associated changes. ibid. 100: 1, 1941.

7. Davson, H. A textbook of general physiol. London: J. and A. Churchill, 258, 1951. 